\title{
Functional walking capacity of subjects with paralyzed knee extensors while walking with an SCO in locked vs unlocked mode
}

\author{
Sarah Schröder1,*, Eva Pröbsting, Thomas Schmalz, Andreas Kannenberg and Hartmut Stinus \\ Ottobock SE \& Co. KGaA, Max-Näder-Straße 15, 37115 Duderstadt, Germany
}

\begin{abstract}
People with a paresis or paralysis of the knee extensors depend on knee-ankle-foot orthoses (KAFOs) to restore walking ability. Unlike locked KAFOs whose orthotic knee joints are only unlocked for sitting down, stance control orthoses (SCOs) may utilize various mechanisms to lock the orthotic knee joint during the stance phase and unlock it for a free swing phase. Thus far, all studies comparing SCOs to locked KAFOs have only used laboratory-based measures, but no clinical performance measures commonly used in rehabilitation medicine. Therefore, the aim of this study was to investigate functional walking capacity using the 6-minute walk test (6MWT), combined with objective 3D gait measurements, in established SCO users when using the orthosis in the unlocked and locked mode, respectively. In addition, satisfaction with the SCO was surveyed using the QUEST questionnaire. A total of eight subjects participated in this study. The results show that in the locked condition, subjects walked a significantly shorter distance $(284.4 \pm 53.0 \mathrm{~m}$ vs. $316.9 \pm 59.6 \mathrm{~m}, \mathrm{p}=.04)$ in the $6 \mathrm{MWT}$ than in the unlocked condition. Gait was more physiological in the unlocked mode with a mean knee flexion angle during swing of $57^{\circ} \pm 15^{\circ}$ vs. full extension in the locked mode. QUEST scores showed a high overall satisfaction with the E-MAG Active SCO.
\end{abstract}

Compared to the unlocked condition, the locked mode imposed a clinically meaningful restriction to the functional walking capacity on the subjects. Therefore, fitting of an SCO may be considered beneficial in individuals dependent on a KAFO to improve their functional walking capacity.

\section{Background}

In total or partial weakness of knee extensors, patients are usually fitted with a custom Knee Ankle Foot Orthoses (KAFO), mostly with a manually locked knee joint that provides safety while walking and can be released for sitting down [1-3]. Orthoses with locked knee joints (locked KAFOs) restore basic walking capabilities but have considerable biomechanical and clinical disadvantages compared to normal walking [4-6]. To avoid stumbles when walking, the patient usually uses hip hiking and sometimes even unnatural plantar flexion during mid-stance on the sound side (vaulting) to provide sufficient toe clearance during swing [7]. Stance Control Ort hoses (SCOs) were introduced to mitigate these limitations. Although they provide the required safety by locking the knee joint for stance, they also enable free knee flexion during the swing phase.

If the patient has sufficient residual function of the paretic leg to safely operate one of the available mechanisms to lock and unlock the orthotic knee joint, SCOs have clear known benefits over locked KAFOs. These are greater toe clearance, more physiologic gait pattern, faster walking speed and lower metabolic energy expenditure. In addition, reduced compensatory movements may be observed. Because of these benefits, patient satisfaction may be increased [4-6,8-10].

Thus far, all studies comparing SCOs tolocked KAFOs have only used laboratory-based measures such as 3D gait measurements, metabolic energy expenditure in treadmill walking, and electromyography assessments, but no clinical performance measures commonly used in rehabilitation medicine. Therefore, the aim of this study was to investigate, for the first time to the best of our knowledge, functional walking capacity using the 6 -minute walk test (6MWT), combined with objective 3D gait measurements, in established SCO users when using the orthosis in the unlocked and locked mode, respectively.

\section{Methods}

\section{Design}

This study was a randomized $2 \times 2$ crossover design study in which each patient served as his or her own control. The study enrolled subjects who had already been using an SCO with the E-MAG Active orthotic knee joint. The intervention was to perform the $6 \mathrm{MWT}$ and motion capture with the knee joint unlocked (A) and locked (B) in randomized order. The order of the test conditions (A-B or B-A) was sealed in envelopes. All participants gave written informed consent to participate in this study. The study was approved by the ethics committee of the state medical council of Niedersachsen, Germany. First, all subjects completed the QUEST questionnaire to rate their satisfaction with the SCO. Then they performed the 6MWT and the gait analysis with the SCO in locked and unlocked conditions with a rest period of two hours between the conditions.

\section{Investigational device}

The E-MAG Active (Ottobock SE \& Co. KGaA, Duderstadt, Germany) [11] is an orthotic knee joint for custom orthoses providing

Correspondence to: Sarah Schröder, M.Sc., Ottobock SE \& Co. KGaA, Duderstadt, Germany, E-mail: sarah.schroeder@ottobock.de

Key words: orthotic device, six minute walk test, stance control orthosis

Received: April 03, 2018; Accepted: April 17, 2018; Published: April 20, 2018 
a locked stance phase and free swing phase. As a requirement for using the functions of this SCO, the user must be able to fully extend the orthotic knee joint at the end of the swing phase to re-lock the orthosis for stance. During the entire stance phase, the orthosis remains locked. The knee automatically unlocks at terminal stance when an extension moment is acting on the knee and the thigh segment angle exceeds an adjustable, patient-specific angular threshold. The patient's knee joint can then move freely during the swing phase. The lock and release mechanisms work independently from the ankle joint. The foot part is usually equipped with an orthotic ankle joint with a dorsal stop that produces a knee extension moment at terminal stance.

\section{Inclusion and exclusion criteria}

Participants had to be at least 18 years old, have a maximal body weight of $100 \mathrm{~kg}$, had to have been using an SCO with the E-MAG Active for at least one year and be willing to participate in the study. Additionally, the users had to be able to walk a total of 20 minutes without a break with both the E-MAG Active in the locked and unlocked conditions.

\section{Outcome measures}

\section{Functional walking capacity}

Subjects' ambulation capacity was assessed with the distance walked in the 6MWT [12] performed on a $14 \mathrm{~m}$ long walkway, with the E-MAG Active knee joint in the locked and unlocked conditions, respectively. The instruction to the subjects was to "walk as far as you can in 6-minutes".

\section{$3 \mathrm{D}$ gait measurements}

3D gait analysis measurements were obtained during level walking with the SCO in the unlocked and locked conditions using an optoelectronic 12-camera system recording kinematic values (120 $\mathrm{Hz}$, VICON giganet, Oxford Metrics, Oxford, GB) combined with two force plates measuring ground reaction forces $(1080 \mathrm{~Hz}$, Kistler 9287A, Kistler AG, Winterthur, CH). Kinematic measurements were conducted by monitoring 21 retroreflective markers attached to the body according to a self-developed model described in a previous publication [13].

\section{Satisfaction}

Subjects' satisfaction with the E-MAG Active SCO was assessed once with the Quebec User Evaluation of Satisfaction with assistive Technology (QUEST, Version 2.0) questionnaire. The QUEST asks for a rating of 12 satisfaction items, eight of which are related to the device, and the remaining four to the service around the device. Each item is rated on a 5-point scale, with a score of 1 denoting "not satisfied at all" and 5 indicating that the person is "very satisfied". Additionally, the user was asked to select the three of these 12 satisfaction items that are the most important ones to him or her [14-16].

\section{Statistical analysis}

The Wilcoxon signed-rank test was used to statistically compare the results between the unlocked and locked conditions with a preset power of $80 \%$ in WinSTAT for MS Excel' (Microsoft Corp., Redmond, WA, USA). Differences between conditions with $\mathrm{p} \leq .05$ were considered statistically significant.

\section{Results}

\section{Demographic data of the subjects}

A total of eight subjects ( 3 female) with an average age of 46.9 $( \pm 19.0)$ years and an average weight of $80.0( \pm 11.5) \mathrm{kg}$ participated in this study. The E-MAG Active knee joint system had been used by the participants for an average of $3.3( \pm 1.6)$ years. The underlying etiologies were incomplete spinal cord injuries (4 patients), poliomyelitis (3 patients) and myopathy (1 patient). The right leg was the affected side in six subjects. The affected legs showed clearly weakened muscle strength in all subjects with the knee extensor strength not exceeding grade one in the manual muscle test. The demographic data is shown in Table 1.

\section{Functional walking capacity}

With the SCO locked, subjects walked a shorter distance in the 6MWT (mean \pm SD: $284.4 \pm 53.0 \mathrm{~m}$ ) than in the unlocked condition (mean \pm SD: $316.9 \pm 59.6 \mathrm{~m}$ ). The difference in the distance walked of $32.5 \pm 29.5 \mathrm{~m}$ was statistically significant $(\mathrm{p}=.04)$.

\section{D Gait Measurements}

The time-distance-parameters are shown in Table 2. The walking speed was significantly faster with the SCO in the unlocked mode. Furthermore, gait symmetry was marginally improved.

As shown in Figure 1A, during walking with the SCO unlocked, there was a mean knee flexion angle of $57^{\circ} \pm 15^{\circ}$ at about $70 \%$ of the gait cycle compared to full extension of the knee during walking in the locked condition. Every subject showed an increased knee flexion angle during swing with the SCO unlocked within a range between $31^{\circ}$ and $80^{\circ}$.

Compensatory movements were reduced with the SCO in the unlocked mode. More specifically, hip hiking was reduced in 6 out of 8 subjects based on the angle of pelvis tilt (obliquity) in the coronal plane. Additionally, vaulting was reduced in 2 out of 3 subjects based on the sagittal angle and moment of the ankle. An example of one patient for both compensatory movements is shown in Figure 1B \& C.

\section{Satisfaction}

The mean ratings of the Device subscale score were $4.4 \pm 0.3$, Service subscale score $4.8 \pm 0.3$, and the Total QUEST score was $4.6 \pm 0.3$. The mean ratings for each question are shown in Table 3.

As far as the importance of the satisfaction items for the patients is concerned, safety was selected most often ( 7 times) with an average rating of 3.8, followed by adjustments and effectiveness (each selected 3 times) with mean ratings of 4.8 and 4.6 , respectively. The items ease of use, comfort, repairs/servicing and professional service were selected twice each; whereas durability, service delivery and follow-up service were only selected once each.

\section{Discussion}

Timed walk tests are validated measures of physical performance and overall mobility in the elderly and patients with various medical conditions [17-21], including incomplete spinal cord injury [2227], post-polio syndrome [28-30] and lower limb amputations [3134]. In subjects with lower limb amputations, the distance walked is well correlated with daily activity and indicative for substantial functional limitations in daily life [33,34].Timed walk tests have not yet been validated specifically for users of KAFOs, but for patients with neurologic conditions that may require fitting of a KAFO such 


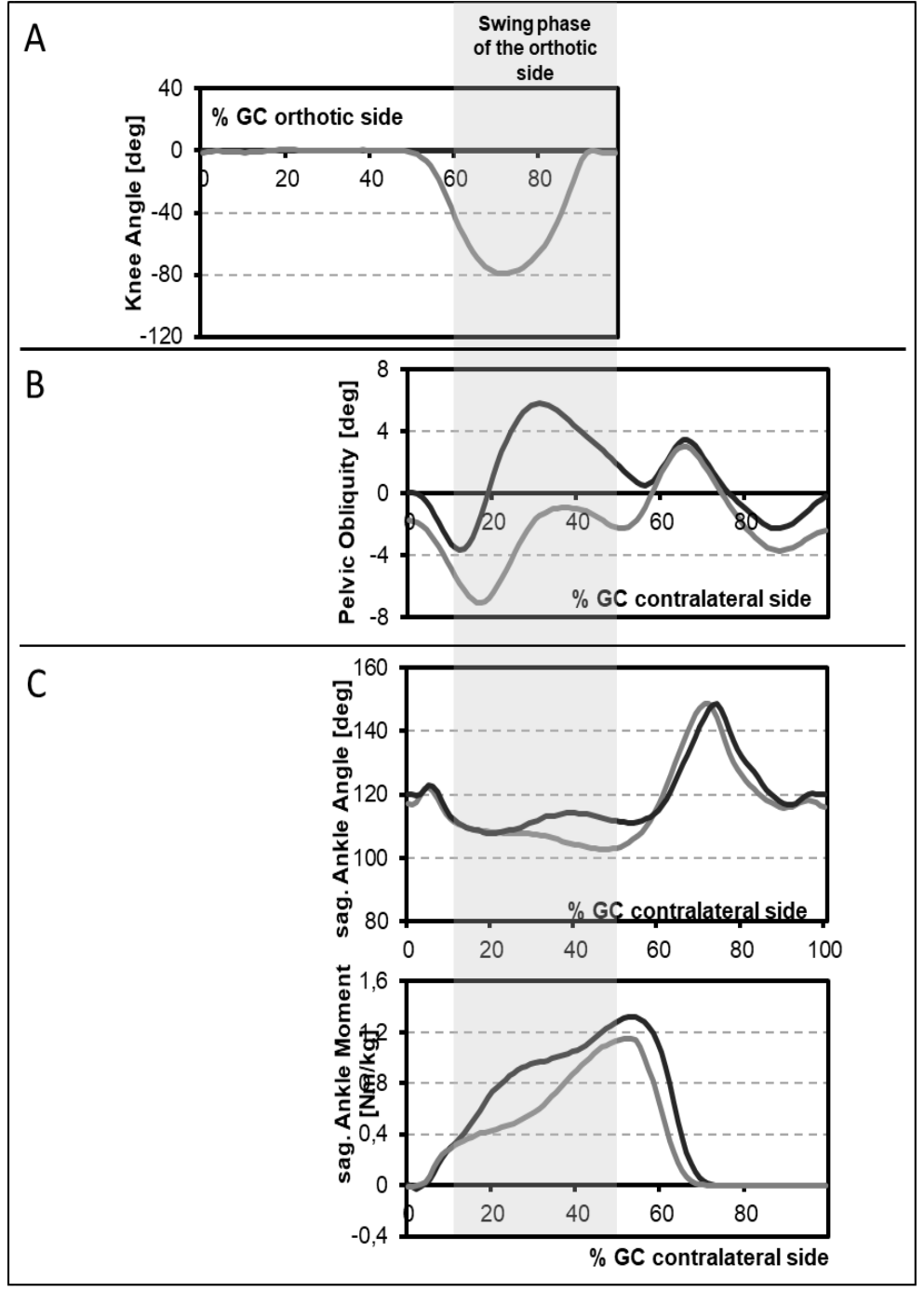

Figure 1. Biomechanical parameters exemplified for one subject. A) Knee flexion angle with the E-MAG in the locked mode; B) Pelvic obliquity; C) Contralateral vaulting, shown with the sagittal angle of the ankle (above) and the sagittal ankle moment (bottom). All parameters are measured during gait with E-Mag in the locked (dark grey) and the unlocked mode (light grey).

Table 1. Demographic data of the eight subjects.

\begin{tabular}{|c|c|c|c|c|c|c|c|c|c|c|c|c|}
\hline \multirow{2}{*}{$\begin{array}{c}\text { Patient- } \\
\text { code } \\
{[\#]}\end{array}$} & \multirow[b]{2}{*}{$\begin{array}{c}\text { Age } \\
\text { [years] }\end{array}$} & \multirow{2}{*}{ 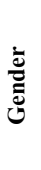 } & \multirow[b]{2}{*}{$\begin{array}{c}\text { Weight } \\
{[\mathrm{kg}]}\end{array}$} & \multicolumn{2}{|c|}{$\begin{array}{l}\text { E-MAG } \\
\text { side }\end{array}$} & \multicolumn{6}{|c|}{$\begin{array}{l}\text { Results of the manual muscle testing on the affected leg } \\
\qquad(0-5)\end{array}$} & \multirow[b]{2}{*}{ Indication } \\
\hline & & & & $\stackrel{ \pm 0}{=00}$ & 흘 & 刍 & 音 & 兽 & 离 & 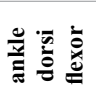 & 产站咅 & \\
\hline 2622 & 33 & $\mathrm{w}$ & 68.5 & $\mathrm{x}$ & & 2 & 3 & 0 & 0 & 0 & 0 & spinal cord injury \\
\hline 1272 & 72 & $\mathrm{~m}$ & 94 & $\mathrm{x}$ & & 3 & 3 & 0 & 0 & 0 & 0 & spinal cord injury \\
\hline 2384 & 63 & $\mathrm{~m}$ & 88 & $\mathrm{x}$ & & 5 & 4.5 & 0 & 4.5 & 1 & 4.5 & poliomyelitis \\
\hline 2695 & 45 & $\mathrm{~m}$ & 68.5 & $\mathrm{x}$ & & 1.5 & 5 & 1 & 0 & 0 & 0 & illness of the muscle \\
\hline 2705 & 27 & $\mathrm{w}$ & 73 & $\mathrm{x}$ & & 1 & 2.5 & 0 & 0 & 0 & 0 & spinal cord injury \\
\hline 2706 & 20 & $\mathrm{w}$ & 80 & $\mathrm{x}$ & & 0 & 1 & 0 & 0 & 0 & 0 & poliomyelitis \\
\hline 2652 & 64 & $\mathrm{~m}$ & 97.5 & & $\mathrm{x}$ & 2 & 4 & 2 & 1 & 0 & 0 & poliomyelitis \\
\hline 2738 & 51 & $\mathrm{~m}$ & 72.5 & & $\mathrm{x}$ & 2 & 3 & 0 & 1 & 1 & 1 & spinal cord injury \\
\hline
\end{tabular}

Table 2. Time-distance-parameters for the locked and unlocked mode (v: walking speed, $\Delta$ SL: difference in stride length, and $\Delta$ SDL: difference in stance phase length between orthotic and contralateral side).

\begin{tabular}{|c|c|c|c|}
\hline & E-MAG locked & E-MAG unlocked & significant \\
\hline Walking speed $[\mathrm{m} / \mathrm{s}]$ & 0.88 & 0.94 & $\mathrm{P}<.05$ \\
\hline \multicolumn{4}{|l|}{ Gait symmetry } \\
\hline - $\Delta \mathrm{SL}[\mathrm{m}]$ & 0.05 & 0.03 & n.s. \\
\hline - $\Delta \mathrm{SDL}[\% \mathrm{GC}]$ & 7.3 & 6.5 & n.s. \\
\hline
\end{tabular}


Table 3. The questions and mean ratings (mean) with standard deviation (sd) of the QUEST Total sore and both subscale scores $(1=$ not satisfied at all; $2=$ not very satisfied; $3=$ more or less satisfied; $4=$ quite satisfied; $5=$ very satisfied).

\begin{tabular}{|c|c|c|c|c|c|}
\hline & & & Question & mean & sd \\
\hline \multirow{9}{*}{ 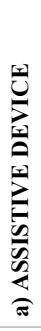 } & \multirow{8}{*}{ 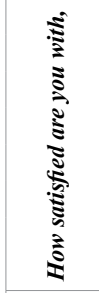 } & dimension & the size, length, width of your assistive device & 4.5 & 0.5 \\
\hline & & weight & the weight of your assistive device & 4.5 & 0.8 \\
\hline & & adjustments & the ease in adjusting (fixing, fastening) the parts of your assistive device & 4.8 & 0.7 \\
\hline & & safety & how safe and secure your assistive device is & 3.9 & 0.9 \\
\hline & & durability & the durability of your assistive device & 4.2 & 1.2 \\
\hline & & ease to use & how easy it is to use your assistive device & 4.3 & 0.9 \\
\hline & & comfort & how comfortable your assistive device is & 4.8 & 0.5 \\
\hline & & effective-ness & how effective your assistive device is & 4.6 & 0.5 \\
\hline & \multicolumn{3}{|c|}{ Device Subscale Score } & 4.4 & 0.3 \\
\hline \multirow{6}{*}{ 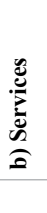 } & \multirow{4}{*}{ 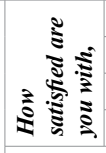 } & service delivery & the service delivery program in which you obtained your assistive device & 4.4 & 1.1 \\
\hline & & repairs / servicing & the repairs and servicing provided for your assistive device & 4.9 & 0.4 \\
\hline & & professional services & the quality of the professional services you received for using your assistive device & 5.0 & 0.0 \\
\hline & & follow-up services & the follow-up services received for your assistive device & 4.9 & 0.2 \\
\hline & \multicolumn{3}{|c|}{ Service Subscale Score } & 4.8 & 0.3 \\
\hline & \multicolumn{3}{|c|}{ Total QUEST Score } & 4.6 & 0.3 \\
\hline
\end{tabular}

as incomplete SCI, stroke, traumatic brain injury, or multiple sclerosis [35-40].

The results of our study show that subjects walked significantly slower in the locked mode compared to the unlocked mode of the SCO. The average difference in walking speed between the orthotic modes was bigger in the $6 \mathrm{MWT}$ with $0.09 \mathrm{~m} / \mathrm{s}$ than in the gait analysis with 0.06 $\mathrm{m} / \mathrm{s}$. In the literature, seven studies reported comparable parameters determined in 3D gait measurements. In five of these studies, subjects demonstrated a significantly faster or at least a tendency toward faster walking speed between $0.06 \mathrm{~m} / \mathrm{s}$ and $0.1 \mathrm{~m} / \mathrm{s}$ with the SCO compared to a locked KAFO $[4,6,8,9,41]$ that corresponds well with the differences found in our study. With the E-MAG Active in the locked condition, subjects were significantly restricted in their functional walking capacity as demonstrated by a mean $32.5 \mathrm{~m}$ reduction in the distance walked in 6 minutes. This difference and thus the effect of the SCO mode on the functional walking capacity is close to the reported minimal clinically important differences (MCID) for incomplete SCI (36 m) [22] and stroke rehabilitation (34.4 m) [36] and also comparable to the effect of a 3-months physical therapy program in polio survivors $(40 \mathrm{~m})$ [42]. Using the SCO mode, subjects reached almost exactly the normative value of $316.8 \mathrm{~m}$ reported for subjects after 12 months of rehabilitation after an incomplete spinal cord injury [35]. Thus, it can be concluded that walking with an orthosis with a locked knee joint results in a significantly reduced functional walking capacity as compared to walking with an SCO with an unlocked knee.

To the best of our knowledge, the 6MWT had never been used before to assess the walking capacity of KAFO users. Our results demonstrate that the difference in walking speed in the 6MWT was bigger than in the short distance gait analysis. This suggests that labbased assessments alone may not be sufficient to evaluate interventions as they may underestimate the magnitude of clinical benefits compared to clinical outcome measures.

The difference in walking distance or walking speed, respectively, between the orthotic modes is probably caused by the fact that walking with a locked orthotic knee requires a multitude of compensatory movements such as hip hiking and vaulting to generate enough toe clearance to prevent stumbles and falls $[4-7,43,44]$. We were able to confirm these compensatory movements in our sample when walking with the orthosis in the locked mode. However, when walking with the SCO with the knee joint unlocked, we found an average knee swing flexion angle of $57^{\circ} \pm 15^{\circ}$, which is in line with the results of previous studies that found knee swing flexion angles between $29^{\circ}$ and $65^{\circ}$ across their subject samples [6,41,43-46]. Physiologically, sound humans walk with a knee flexion angle of about $65^{\circ}$ between $40-75 \%$ of the gait cycle, representing an important contributor to sufficient toe clearance of the swinging leg $[47,48]$. As the orthotic knee joint allows for bending and thus sufficient toe clearance during swing, compensatory movements may be substantially reduced: Lifting of the pelvis on the orthotic side may be diminished and untimely plantar flexion of the sound foot may be reduced, resulting in a decreased sagittal ankle moment (Figure 1).

These results are in accordance with previous studies. Zissimopoulos, et al. [44] and Irby, et al. [41] showed significantly reduced pelvic obliquity on the orthotic side with the SCO compared to a locked orthosis. Schmalz, et al. [6] reported that the pelvic movement when walking with an SCO was comparable to that of healthy subjects. Irby, et al. [41] described a significant reduction in vaulting of the sound side with an SCO, and Hebert \& Liggins [43] reported even no unnatural sound side plantar flexion at all in the middle of the stance phase.

In addition to the objective assessments, we also surveyed participants' satisfaction with the SCO using the QUEST. The ratings of the Device subscale score, Service subscale score and Total QUEST score had a mean value $>4$, which represents a very high overall satisfaction. Wessels \& de Witte [49] analyzed satisfaction with the QUEST in a group of individuals using unspecified orthoses and shoe adaptations. In this group, the mean satisfaction with the device was only 3.9 compared to 4.4 in our study, and the satisfaction with the service was also lower than in our sample (3.8 vs. 4.8). Thus, satisfaction with the SCO used at study entry may be slightly above average for orthotic devices in genera 1 .

We identified three other studies that assessed users' satisfaction with an SCO. These did not use the QUEST but self-developed questionnaires and found a high satisfaction of users with the SCO $[4,9,50]$.

In our study, the most important satisfaction item was "safety". Although subjects were, on average, "quite satisfied" with the safety of the SCO, the somewhat lower rating compared to the other items may reflect the known challenges to consistently control the functional mechanisms of an SCO. A general characteristic of all SCOs is that the proper function of the orthosis, especially the locking for stance and unlocking for swing, must be controlled by the patient. This requires 
certain residual functions and a permanent concentration on the gait. It is quite likely that users have experienced in their daily lives, for example in situations with increasing physical fatigue, that the locking of the orthotic knee joint may be vulnerable [51]. Research and development have meanwhile addressed some of the technical challenges of the control mechanisms of SCOs. While this study enrolled users of the previous version of the E-MAG Active that required full extension of the orthosis at terminal swing to lock the knee for safe heel strike, the current versions may lock the knee in two positions at $5^{\circ}$ or $7.5^{\circ}$ and $15^{\circ}$ knee flexion. Clinical decision making may meanwhile also consider a microprocessor controlled hydraulic orthotic knee joint that enables knee flexion during weight bearing as required for reciprocal slope and stair descent and provides increased perceived safety in many activities of daily living [51,52].

\section{Limitations}

This study has several limitations. At enrollment, the subjects had already been using the SCO with the E-MAG Active knee joint in their daily lives. It might be a concern that they were not given any training or accommodation to readjust to the locked mode. However, the difference in walking speed between the locked and unlocked mode in both the gait analysis and the 6MWT did not exceed the differences found in previous studies that had enrolled users of locked KAFOs who were then fitted an SCO as the study intervention. Thus, there is no indication that our subjects were not proficient enough in the use of the locked mode. Furthermore, there is no consensus on the optimal accomodation time to orthotic interventions. Acclimmation periods in orthotic studies have ranged from minutes to 3 months. Therefore, our inclusion criterion of E-MAG Active use of at least 1 year may have favored very proficient and well accommodated users. Satisfaction was only assessed for the SCO and could not be obtained for the locked mode as the latter was only used for the tests. Due to the obivous differences between walking with a locked or unlocked orthosis, blinding of participants and assessors was impossible. These factors may impose a bias to the results.

\section{Conclusion}

In conclusion, fitting of an SCO may be considered beneficial when a subject dependent on a KAFO presents the residual functions necessary to safely control it.

\section{Declaration of conflict interest}

Sarah Schröder, Eva Pröbsting, Thomas Schmalz, and Andreas Kannenberg are full time employees of Ottobock SE \& Co. KGaA, the manufacturer of the E-Mag Active. The expenditures of Dr. Stinus related to this study were paid for by Ottobock SE \& Co. KGaA, Germany.

\section{Source of Funding}

The author(s) who are full time employees of Ottobock SE \& Co. $\mathrm{KGaA}$ disclosed receipt of the following financial support for the research, authorship, and/or publication of this article: Ottobock SE \& Co. KGaA allowed the authors to work on the article during their regular work hours and use the company's office equipment (computers, Internet access, Gait Lab, etc). Dr. Stinus was paid for his work hours by Ottobock SE \& Co. KGaA.

\section{References}

1. Baehler AR, Bieringer S (2007) Orthopädietechnische Indikationen. Publisher Hans Huber, 2nd Edition.
2. Hohmann D, Uhlig R (2004) Orthopädische Technik. Publisher Georg Thieme, 9th Edition.

3. Specht J, Schmitt M, Pfeil J (2007) Technische Orthopädie. Publisher Springer Berlin, Heidelberg, 1st Edition.

4. Bernhardt KA, Irby SE, Kaufman KR (2006) Consumer opinions of a stance control knee orthosis. Prosthet Orthot Int 30: 246-256. [Crossref]

5. Irby SE, Bernhardt KA, Kaufman KR (2005) Gait of stance control orthosis users: the dynamic knee brace system. Prosthet Orthot Int 29: 269-282. [Crossref]

6. Schmalz T, Blumentritt, S, Drewitz H (2005) Gangphasenabhängig entriegelnde versus gesperrte Beinorthesen - Biomechanische und metabolische Untersuchungen. Unlocking versus locking leg orthosis during gait performance - Biomechanical and metabolic case studies. Medizinisch Orthopädische Technik 3: 67-74.

7. Zacharias B, Kannenberg A (2012) Clinical Benefits of Stance Control Orthosis Systems: An Analysis of the Scientific Literature. J Prosth Orthot 24: 2-7.

8. Davis PC, Bach TM, Pereira DM (2010) The effect of stance control orthoses on gait characteristics and energy expenditure in knee-ankle-foot orthosis users. Prosthet Orthot Int 34: 206-215. [Crossref]

9. McMillan AG, Kendrick K, Michael JW, Aronson J, Horton GW (2004) Preliminary evidence for effectiveness of a stance control orthosis. J Prosth Orthot 16: 6-13.

10. Sabelis L, van Schie C, Noppe C (2007) Use and appreciation of stance-control KAFOs in patients with polio residuals. In 12 th World Congress of the International Society for Prosthetics and Orthotics, Vancouver, Canada.

11. Otto Bock HealthCare GmbH. E-MAG Active - Information for Practitioners.

12. American Thoracic Society (2002) Guidelines for the six minute walk test. Am J Respir Crit Care Med 166: 111-117. [Crossref]

13. Ludwigs E, Bellmann M, Schmalz T, Blumentritt S (2010) Biomechanical differences between two exoprosthetic hip joint systems during level walking. Prosthet Orthot Int 34: 449-460. [Crossref]

14. Demers L, Weiss-Lambrou R, Ska B (1996) The Quebec User Evaluation of Satisfaction with assistive Technology: QUEST. Assist Technol 8: 3-13.

15. Demers L, Weiss-Lambrou R, Ska B (1997) Quebec User Evaluation of Satisfaction with assistive Technology (QUEST): A new outcome measure. Proceedings of the RESNA 97 Annual Conference - Let's Tango Partnering people and technologies (pp. 94-96). David L. Lawrence Convention Center, Pittsburgh, Pennsylvania.

16. Weiss-Lambrou R, Demers L, Tremblay C, Ska B, Lacoste M, et al. (1997) In QUEST of user satisfaction with assistive technology devices. In G. Anogianakis, C. Bühler, M. Soede (1997), Advancement of Assistive Technology, Assistive Technology Research Series, 3: 428-431, Washington, DC: IOS Press.

17. Brooks D, Parsons J, Tran D, Jeng B, Gorczyca B, et al. (2004). The two-minute walk test as a measure of functional capacity in cardiac surgery patients. Arch Phys Med Rehabil 85: 1525-1530. [Crossref]

18. Brooks D, Davis AM, Naglie G (2006) Validity of 3 physical performance measures in inpatient geriatric rehabilitation. Arch Phys Med Rehabil 87: 105-110. [Crossref]

19. Brooks D, Davis AM, Naglie G (2007) The feasibility of six-minute and two-minute walk tests in in-patient geriatric rehabilitation. Can J Aging 26: 159-162. [Crossref]

20. Connelly DM, Thomas BK, Cliffe SJ, Perry WM, Smith RE (2009) Clinical utility of the 2-minute walk test for older adults living in long-term care. Physiother Can 61: 78-87. [Crossref]

21. Rossier P, Wade DT (2001) Validity and reliability comparison of 4 mobility measures in patients presenting neurologic impairment. Arch Phys Med Rehabil 82: 9-13. [Crossref]

22. Forrest GF, Hutchinson K, Lorenz DJ, Buehner JJ, Vanhiel LR, et al. (2014) Are the 10 meter and 6 minute walk tests redundant in patients with spinal cord injury? PLoSone 9: e94108. [Crossref]

23. Jackson AB, Carnel CT, Ditunno JF, Read MS, Boninger ML, et al. (2008) Outcome measures for gait and ambulation in the spinal cord injury population. J Spinal Cord Med 31: 487-499. [Crossref]

24. Lam T, Noonan V, Eng JJ (2007) A systematic review of functional ambulation outcome measures in spinal cord injury. Spinal Cord 46: 246-254. [Crossref]

25. Olmos LE, Freixes O, Gatti MA, Cozzo DA, Fernandez SA, et al. (2008) Comparison of gait performance on different environmental settings for patients with chronic spinal cord injury. Spinal Cord 46: 331-334. [Crossref] 
26. van Hedel HJ, Wirz M, Curt A (2006) Improving walking assessment in subjects with an incomplete spinal cord injury: responsiveness. Spinal Cord 44: 352-356. [Crossref]

27. van Hedel HJ, Wirz M, Dietz V (2005) Assessing walking ability in subjects with spina cord injury: validity and reliability of 3 walking tests. Arch Phys Med Rehabil 86: 190196. [Crossref]

28. Flansbjer UB, Lexell J (2010) Reliability of gait performance tests in individuals with late effects of polio. PM R 2: 125-131. [Crossref]

29. Horemans HL, Beelen A, Nollet F, Lankhorst GJ (2004) Reproducibility of walking at self-preferred and maximal speed in patients with postpoliomyelitis syndrome. Arch Phys Med Rehabil 85: 1929-1932. [Crossref]

30. Stolwijk-Swüste JM, Beelen A, Lankhorst GJ, Nollet F, CARPA study group (2008) SF36 physical functioning scale and 2-minute walk test advocated as core qualifiers to evaluate physical functioning in patients with late-onset sequelae of poliomyelitis. $J$ Rehabil Med 40: 387-392. [Crossref]

31. Brooks D, Parsons J, Hunter JP, Devlin M, Walker J (2001) The 2-minute walk test as a measure of functional improvement in persons with lower limb amputation. Arch Phys Med Rehabil 82: 1478-1483. [Crossref]

32. Brooks D, Hunter JP, Parsons J, Livsey E, Quirt J, et al. (2002) Reliability of the twominute walk test in individuals with transtibial amputation. Arch Phys Med Rehabil 83 : 1562-1565. [Crossref]

33. Gremeaux V, Damak S, Troisgros O, Feki A, Laroche D, et al. (2012) Selecting a test for the clinical assessment of balance and walking capacity at the definitive fitting state after unilateral amputation: a comparative study. Prosthet Orthot Int 36: 415-422. [Crossref]

34. Parker K, Kirby RL, Adderson J, Thompson K (2010) Ambulation of people with lower-limb amputation: Relationship between capacity and performance measures. Arch Phys Med Rehabil 91: 543-549. [Crossref]

35. Ditunno JF, Barbeau H, Dobkin BH, Elashoff R, Harkema S, et al. (2007) Spinal Cord Injury Locomotor Trial Group. Validity of the walking scale for spinal cordinjury and other domains of function in a multi center clinical trial. Neurorehabil Neural Repair 21: 539-550.

36. Eng JJ, Dawson AS (2004) Submaximal exercise in persons with stroke: test-retest reliability and concurrent validity with maximal oxygen consumption. Arch Phys Med Rehabil 85: 113-118. [Crossref]

37. Flansbjer UB, Holmback AM, Downham D, Patten C, Lexell J (2005) Reliability of gait performance tests in men and women with hemiparesis after stroke. J Rehabil Med 37: 75-82. [Crossref]

38. Gijbels D, Alders G, Van Hoof E, Charlier C, Roelants M, et al. (2010) Predicting habitual walking performance in multiple sclerosis: relevance of capacity and selfreport measures. Mult Scler 16: 618-626. [Crossref]
39. Gijbels D, Eijnde BO, Feys P (2011) Comparison of the 2- and 6-minute walk test in multiple sclerosis. Mult Scler 17: 1269-1272. [Crossref]

40. Moseley AM, Lanzarone S, Bosman JM, van Loo MA, de Bie RA, et al. (2004) Ecological validity of walking speed assessment after traumatic brain injury: a pilot study. J Head Trauma Rehabil 19: 341-348. [Crossref]

41. Irby SE, Bernhardt KA, Kaufman KR (2007) Gait changes over time in stance control orthosis users. Prosthet Orthot Int 31: 353-361. [Crossref]

42. Bertelsen M, Broberg S, Madsen E (2009) Outcome of physiotherapy as part of a multidisciplinary rehabilitation in an unselected polio population with one-year followup: an uncontrolled study. J Rehabil Med 41: 85-87. [Crossref]

43. Hebert JS, Liggins AB (2005) Gait evaluation of an automatic stance-control knee orthosis in a patient with postpoliomyelitis. Arch Phys Med Rehabil 86: 1676-1680. [Crossref]

44. Zissimopoulos A, Fatone S, Gard SA (2007) Biomechanical and energetic effects of a stance-control orthotic knee joint. J Rehabil Res Dev 44: 503-513. [Crossref]

45. Moreno JC, Brunetti F, Rocon E, Pons JL (2008) Immediate effects of a controllable knee ankle foot orthosis for functional compensation of gait in patients with proximal leg weakness. Med Biol Eng Comput 46: 43-53. [Crossref]

46. Yakimovich T, Lemaire ED, Kofman J (2006) Preliminary kinematic evaluation of a new stance-control knee-ankle-foot orthosis. Clin Biomech (Bristol, Avon) 21: 10811089. [Crossref]

47. Götz-Neumann Kirsten (2006) Gehen verstehen. Ganganalyse in der Physiotherapie Publisher Thieme, 2nd Edition.

48. Perry Jacqueline (2003) anganalyse. Norm und Pathologie des Gehens. Publisher Urban \& Fischer, 1st Edition.

49. Wessels RD, De Witte LP (2003) Reliability and validity of the Dutch version of QUEST 2.0 with users of various types of assistive devices. Disabil Rehabil 25: 267272. [Crossref]

50. Swinnen E, Lafosse C, Van Nieuwenhoven J, Ilsbroukx S, Beckwée D, et al. (2015) Neurological patients and their lower limb orthotics: An observational pilot study about acceptance and satisfaction. Prosthet Orthot Int 41: 41-50. [Crossref]

51. Pröbsting E, Kannenberg A, Zacharias B (2016) Safety and walking ability of KAFO users with the $\mathrm{C}$-Brace ${ }^{\mathbb{B}}$, a new microprocessor stance and swing control orthosis. Prosthet Orthot Int 41: 65-77. [Crossref]

52. Schmalz T, Pröbsting E, Auberger R, Siewert G (2016) A functional comparison of conventional knee-ankle-foot orthoses and a microprocessor-controlled leg orthosis system based on biomechanical parameters. Prosthet Orthot Int 40: 277-286. [Crossref]

Copyright: $\odot 2018$ Schröder S. This is an open-access article distributed under the terms of the Creative Commons Attribution License, which permits unrestricted use, distribution, and reproduction in any medium, provided the original author and source are credited. 